\title{
Rubble pile characterization model
}

\author{
W. Schonberg ${ }^{1}$, J. Baird ${ }^{1}$, P. Worsey ${ }^{1}$, A. Belarbi ${ }^{1}$, R. LaBoube ${ }^{1}$, \\ B. Lusk ${ }^{1}$, R. Flanagan ${ }^{2}$, H. Burleson ${ }^{2}$, R. Woodley ${ }^{2} \&$ W. Noll ${ }^{2}$ \\ ${ }^{1}$ University of Missouri-Rolla, Rolla, MO, USA \\ ${ }^{2} 21^{\text {st }}$ Century Systems, Inc., Ft. Leonard Wood, MO, USA
}

\begin{abstract}
Rubble piles created following the collapse of a building in a combat situation can significantly impact mission accomplishment, particularly in the area of movement and maneuver. Rubble characteristics must be known, for example, in order to predict the ability of a vehicle to override the collateral damage from weapon effects in urban areas. Two types of models are developed: a first-order model and a first-principles-based model. In both models, we assume complete rubblization of the building and develop a rubble profile model using the size and composition of the collapsed structure to predict the rubble volume. In both cases, this profile model includes the size of the footprint area surrounding the original building assuming that the rubble is free to expand horizontally as well as the resulting height of such a rubble pile. Empirical data is now needed to verify the predictive capabilities of these models.

Keywords: building collapse, rubble pile.
\end{abstract}

\section{Introduction}

This paper presents a rubble characterization model developed in support of the development of AmmoSIM, an agent-based urban tactical decision aid (UTDA) for weapon-target pairing. AmmoSIM will ultimately be able to provide a fielded graphical lethality and vulnerability analysis tool using a synthetic 3-D urban terrain environment. AmmoSIM is intended to be an "on-the-fly" simulation tool to predict and/or validate weapons effects and employment against targets in an urban environment. As such, it needs to include rubble effects, breakout of fires, infrastructure degradation, and WMD/HAZMAT effluent patterns. Rubble impacts mission accomplishment, particularly in the area of movement and maneuver. As such, rubble characteristics must be known, for example, in order 
to predict ability of a vehicle to override the collateral damage from weapon effects in urban areas.

The development of a robust rubble characterization model is a very complicated problem if all aspects of building collapse and rubble generation are to be considered and characterized in their entireties. To bound the problem and render it tractable, a number of simplifying assumptions have been made.

The model presented herein considers only thick uniform masonry buildings with square or near-square footprints. In addition, the model only considers ground-based directed weapons fire (i.e. weapons coming from a tank or a mortar launching unit), and not blast loads or placed charges since guidelines for building demolition using placed charges are already readily available. The model does not consider armor-piercing projectiles because their primary effect upon impacting the wall of a building is to put a hole in that wall.

Two types of models are developed: a first-order model and a first-principles-based model. In both models, we assume complete rubblization of the building and develop a rubble profile model using the size and composition of the collapsed structure to predict the rubble volume. In both cases, this profile model includes the size of footprint area surrounding original building assuming that the rubble is free to expand horizontally as well as the resulting height of such a rubble pile. The height of rubble pile along its periphery is adjusted based the on proximity of other buildings. These adjacent buildings will be assumed to block rubble dispersion, thereby forcing it to backfill or stack up along the edges of the adjacent buildings that face the center of the collapsed building site.

For the purposes of this study, we assume that the building is without a basement and that it is located in a residential area. It is presumed not to be an office building or a building in a shopping district with significant glazing facing the street. The major effect of whatever windows do exist is to reduce the amount or volume of building material; this effect is introduced through a volume reduction factor of some nominal amount. Figure 1 below presents a sketch of a generic building illustrating a nearly square footprint area.

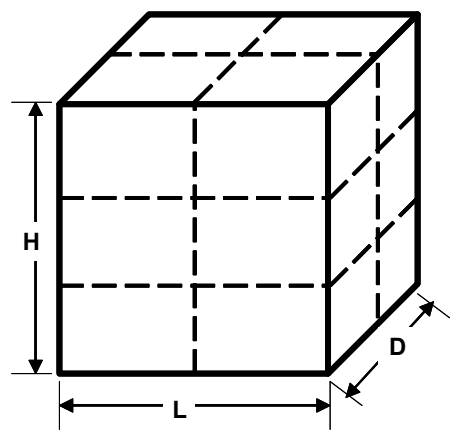

Figure 1: Sketch of generic "boxy" building.

In order to determine the dimensions of the rubble pile following building collapse, we need to know the values of the following geometric parameters: 
L, the length when looking straight at building from firing location; D, the depth of building along line of fire; $\mathrm{H}$, the building height; $\mathrm{N}_{\mathrm{S}}$, the number of stories in building; $\mathrm{N}_{\mathrm{R}}=\mathrm{N}_{\mathrm{RL}} \times \mathrm{N}_{\mathrm{RD}}$, the number of rooms per story (assumed equal for all stories), where $\mathrm{N}_{\mathrm{RL}}$ is the number of rooms along the length of the building and $\mathrm{N}_{\mathrm{RD}}$ is the number of rooms in the building depth direction; $t_{\mathrm{we}}$, the exterior wall thickness (assumed equal for all exterior walls); $t_{w i}$, the interior wall thickness (assumed equal for all interior walls); $t_{\mathrm{fe}}$, the floor thickness (assumed equal for all floors); $t_{r}$, the roof thickness; $d_{b}$, the basement depth.

Other information that is required to develop the rubble pile model is building material properties, the proximity of other buildings to the building of interest, and the weight or energy of explosive used to demolish the building.

\section{Initial calculations}

The first step in calculating the dimensions of the rubble pile is calculating the volume of building material in its upright or functional configuration. This building material volume is given as follows:

Building material volume $=$ volume of 4 exterior walls + volume of $\left(\mathrm{N}_{\mathrm{S}}-1\right)$ floors

+ volume of $\left(\mathrm{N}_{\mathrm{RL}}-1\right)$ interior walls parallel to line of fire + volume of $\left(\mathrm{N}_{\mathrm{RD}}-1\right)$ interior walls perpendicular to line of fire + volume of roof

These quantities are given as follows.

$$
\begin{array}{cc}
\multicolumn{1}{c}{\text { Roof Volume }} & \mathrm{V}_{\mathrm{r}}=\mathrm{LDt}_{\mathrm{r}} \\
\text { Exterior walls (4) volume } & \mathrm{V}_{\mathrm{we}}=2 \mathrm{~L}\left(\mathrm{H}-\mathrm{t}_{\mathrm{r}}\right) \mathrm{t}_{\mathrm{we}}+2 \mathrm{D}\left(\mathrm{H}-\mathrm{t}_{\mathrm{r}}\right) \mathrm{t}_{\mathrm{we}} \\
\text { Volume of } \mathrm{N}_{\mathrm{s}}-1 \text { floors } & \mathrm{V}_{\mathrm{fl}}=\left(\mathrm{N}_{\mathrm{s}}-1\right)\left(\mathrm{L}-2 \mathrm{t}_{\mathrm{we}}\right)\left(\mathrm{D}-2 \mathrm{t}_{\mathrm{we}}\right) \mathrm{t}_{\mathrm{fl}}
\end{array}
$$

The volume of the $\mathrm{N}_{\mathrm{RL}}-1$ interior walls along line of fire is given by

$$
\mathrm{V}_{\mathrm{WRL}}=\mathrm{Ns} \times \mathrm{h}_{\mathrm{L}} \times \mathrm{d}_{\mathrm{D}} \times\left(\mathrm{N}_{\mathrm{RL}}-1\right) \times \mathrm{N}_{\mathrm{RD}} \times \mathrm{t}_{\mathrm{wi}}
$$

where $h_{L}$ is the wall height and $d_{D}$ is the wall depth along the line of fire. These quantities are given as follows:

$$
\begin{gathered}
\mathrm{h}_{\mathrm{L}}=\left[\mathrm{H}-\operatorname{tr}-\left(\mathrm{N}_{\mathrm{s}}-1\right) \mathrm{t}_{\mathrm{fl}}\right] / \mathrm{N}_{\mathrm{s}} \\
\mathrm{d}_{\mathrm{D}}=\left[\mathrm{D}-2 \mathrm{t}_{\mathrm{we}}-\left(\mathrm{N}_{\mathrm{RD}^{-}}-1\right) \mathrm{t}_{\mathrm{wi}}\right] / \mathrm{N}_{\mathrm{RD}}
\end{gathered}
$$

Finally, the volume of $\mathrm{N}_{\mathrm{RD}}-1$ interior walls across the line of fire is given by

$$
\mathrm{V}_{\mathrm{WRD}}=\mathrm{N}_{\mathrm{s}} \times\left(\mathrm{N}_{\mathrm{RD}}-1\right) \times \mathrm{N}_{\mathrm{RL}} \times \mathrm{h}_{\mathrm{L}} \times \mathrm{d}_{\mathrm{L}} \times \mathrm{t}_{\mathrm{wi}}
$$

where $h_{L}$ as before and 


$$
\mathrm{d}_{\mathrm{L}}=\left[\mathrm{L}-2 \mathrm{t}_{\mathrm{we}}-\left(\mathrm{N}_{\mathrm{RL}}-1\right) \mathrm{t}_{\mathrm{wi}}\right] / \mathrm{N}_{\mathrm{RL}}
$$

In the following analysis, we assume that the rubble pile is in the shape of a right circular cone centered about the geometric center of the original building.

\section{First-order model}

In developing a first-order model of the rubble pile, we postulate that the radius of the cone is twice that of the building's average floor half-length. This assumption is consistent with photographic and empirical evidence obtained at building collapse sites.

For example, Yarimer and Brown [1] postulate that as a "collection of blocks falls, it creates a pile of rubble of height $\alpha \Delta \mathrm{h}$, where $\Delta \mathrm{h}$ is the intact structure height converted into rubble." They subsequently use a value of $\alpha=0.15$ to fit their analyses to their experimental data. A simple calculation equating the volume of an $\mathrm{H} \times \mathrm{L} \times \mathrm{D}$ block to that of a cone having a base radius $\mathrm{r}_{\mathrm{c}}$ and a height of $0.15 \mathrm{H}$ yields the result that $\mathrm{r}_{\mathrm{c}}=2.52 \mathrm{~L}=5.04(\mathrm{~L} / 2)$, assuming that $\mathrm{D}$ and $\mathrm{L}$ are comparable in size, as we are doing in this study.

Mathematically then, we have that the rubble cone radius is given by

$$
\mathrm{r}_{\mathrm{c}}=\frac{1}{2} \times \operatorname{avg}(\mathrm{L}, \mathrm{D}) \times 2
$$

The height of the debris pile is then calculated from

$$
\mathrm{V}_{\text {tot }}=\frac{\pi}{3}\left(\mathrm{r}_{\mathrm{c}}^{2}\right) \mathrm{h}_{\mathrm{c}}
$$

where

$$
\mathrm{V}_{\text {tot }}=\mathrm{V}_{\mathrm{r}}+\mathrm{V}_{\mathrm{we}}+\mathrm{V}_{\mathrm{fl}}+\mathrm{V}_{\mathrm{WRL}}+\mathrm{V}_{\mathrm{WRD}}
$$

We note that the total volume $\mathrm{V}_{\text {tot }}$ is multiplied by a bulk-up factor and a window effects factor to account for the bulking up in apparent volume that typically occurs when a compact object is exploded and for the reduction in volume due to the presence of windows in the building of interest.

The actual extent of the rubble debris pile will depend on the proximity of the buildings adjacent to or across the street from the collapsed building. If the rubble pile created would normally extend beyond the distance to the closest building (i.e. if the adjacent building were not there), then it is presumed that the rubble pile will "stack up" next to the adjacent building and a heightening of the rubble would occur near the adjacent building.

If we let $D_{S}$ be the distance between the original building and the closest adjacent building, then back-filling would occur if and only if

$$
\mathrm{r}_{\mathrm{c}} \geq \frac{1}{2} \times \operatorname{avg}(\mathrm{L}, \mathrm{D})+\mathrm{D}_{\mathrm{S}}
$$

If we let $\Delta$ denote the extent beyond the façade of the adjacent building that the rubble would extend if there were no adjacent building, then the height of the backfilled material next to the adjacent building is calculated as follows. 
First, we need to calculate the amount or volume of material that is allowed to "stack up" on top of the original cone volume due to the presence of an adjacent building. Referring to Figure 2 below, AEO is a line running through the geometrical center of the original (upright) building, while DB is the façade of an adjacent building. Line ABC rests on street level.

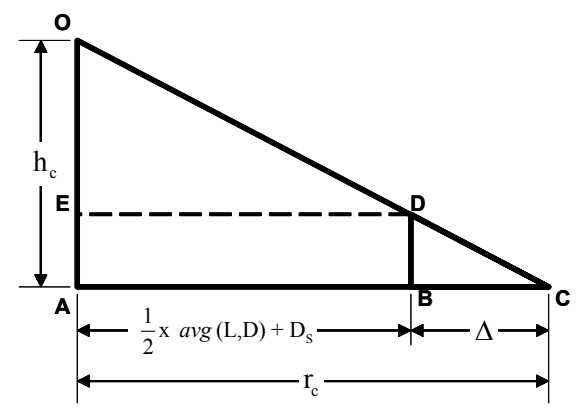

Figure 2: Geometrical considerations for calculating back-fill volume $\mathrm{V}_{\mathrm{BCD}}$.

In this case, the volume of material in the annular cone defined by triangle BCD is the amount of material that stacks up next to the adjoining building, creating this back-fill effect. Using similar triangles, this volume is found to be given as follows.

$$
\begin{gathered}
\mathrm{V}_{\mathrm{BDC}}=\frac{\pi}{3} \mathrm{r}_{\mathrm{c}}{ }^{2} \mathrm{~h}_{\mathrm{c}}-\frac{\pi}{3}\left[\frac{1}{2} \mathrm{x} \operatorname{avg}(\mathrm{L}, \mathrm{D})+\mathrm{D}_{\mathrm{S}}\right]^{2}\left\{\mathrm{~h}_{\mathrm{c}}-\frac{\mathrm{h}_{\mathrm{c}}}{\mathrm{r}_{\mathrm{c}}}\left[\mathrm{r}_{\mathrm{c}}-\left(\frac{1}{2} \mathrm{x} \operatorname{avg}(\mathrm{L}, \mathrm{D})+\mathrm{D}_{\mathrm{S}}\right)\right]\right\}- \\
\pi\left[\frac{1}{2} \mathrm{x} \operatorname{avg}(\mathrm{L}, \mathrm{D})+\mathrm{D}_{\mathrm{S}}\right]^{2}\left\{\mathrm{r}_{\mathrm{c}}-\left[\frac{1}{2} \mathrm{x} \operatorname{avg}(\mathrm{L}, \mathrm{D})+\mathrm{D}_{\mathrm{S}}\right]\right\}
\end{gathered}
$$

where $r_{c}$ and $h_{c}$ are given by equations (10) and (11), respectively.

The next step is to calculate the new profile of the rubble pile due to this back filling of debris material next to the adjacent building. Referring to Figure 3 below, this amounts to calculating distance DD'. For the purposes of this model, the back-filling is assumed to occur linearly from the façade of the adjacent building back to the tip of the cone defining the original debris pile.

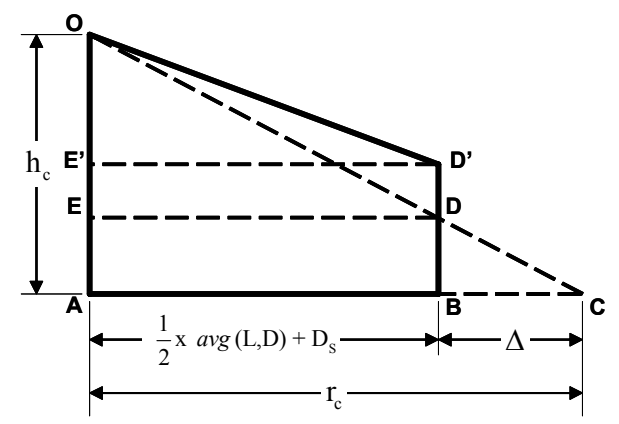

Figure 3: Geometrical considerations for calculating stack-up height DD'. 
We find $\mathrm{DD}^{\prime}$ by noting that the volume of material in the new configuration equals the original volume of cone $\mathrm{OAC}$, or that the volume of cone $\mathrm{OAC}$ equals the volume of cone OE'D' plus the volume of cylinder E'ABD':

$$
\frac{\pi}{3} r_{c}{ }^{2} h_{c}=\frac{\pi}{3}\left(E^{\prime} D^{\prime}\right)^{2}\left(E^{\prime} \mathrm{O}\right)+\pi(A B)^{2}\left(B^{\prime}\right)
$$

Again using similar triangles and other fundamental relationships between the various geometric shapes in Figure 3, we solve for DD' with the result:

$$
\mathrm{DD}^{\prime}=\frac{\mathrm{h}_{\mathrm{c}}}{2}\left\{\frac{\mathrm{r}_{\mathrm{c}}^{2}}{\left[\frac{1}{2} \mathrm{x} \operatorname{avg}(\mathrm{L}, \mathrm{D})+\mathrm{D}_{\mathrm{s}}\right]^{2}}-\left(1+2 \frac{\Delta}{\mathrm{r}_{\mathrm{c}}}\right)\right\}
$$

where $\Delta$ is given by

$$
\Delta=\mathrm{r}_{\mathrm{c}}-\left[\frac{1}{2} \mathrm{x} \operatorname{avg}(\mathrm{L}, \mathrm{D})+\mathrm{D}_{\mathrm{S}}\right]
$$

and length $\mathrm{BD}$ is given by

$$
\mathrm{BD}=\left(\frac{\mathrm{h}_{\mathrm{c}}}{\mathrm{r}_{\mathrm{c}}}\right) \Delta
$$

\section{First-principles-based model}

In the previous section, a first-order model of the rubble pile that is created following building collapse was developed. In the model to be developed in this section, we use the principle of energy conservation to remove this assumption and use a first principles calculation to determine the horizontal extent of the rubble pile. Simply put, we have that the explosive energy is the sum of the energies required for the fragmentation of roof, the ceilings and floors, and all walls plus the energies required for the motion of the fragments emanating from the roof, the ceilings and floors, and all walls.

To be conservative, we assume that all of the explosive energy goes into debris movement; none of it gets applied to fragmentation or debris formation. This should result in more widespread debris, which should render the model more conservative in nature. Furthermore, we assume that the building's roof and its ceilings/floors fall straight down and that their debris do not travel outward (debris from the building's lowest floor is presumed to remain where created). In addition, for this model, we are neglecting lift and drag forces on the rubble pieces as they move through the air and consider only gravity effects. Under these assumptions, we have simply that the explosive energy delivered to the building is transformed to the energy of motion of all the building's walls.

In a building that is $\mathrm{N}_{\mathrm{s}}$ stories high and has $\mathrm{N}_{\mathrm{R}}=\mathrm{N}_{\mathrm{RL}} \times \mathrm{N}_{\mathrm{RD}}$ rooms, the number of walls is found by adding the number of exterior and interior walls as follows: 


$$
\mathrm{N}_{\mathrm{w}}=\mathrm{N}_{\mathrm{w}, \text { ext }}+\mathrm{N}_{\mathrm{w}, \text { int }}
$$

where

$$
\mathrm{N}_{\mathrm{w}, \mathrm{ext}}=2 \times \mathrm{N}_{\mathrm{S}} \times \mathrm{N}_{\mathrm{RL}}+2 \times \mathrm{N}_{\mathrm{S}} \times \mathrm{N}_{\mathrm{RD}}
$$

and

$$
\mathrm{N}_{\mathrm{w}, \text { int }}=\mathrm{N}_{\mathrm{s}} \times \mathrm{N}_{\mathrm{RL}} \times\left(\mathrm{N}_{\mathrm{RD}}-1\right)+\mathrm{N}_{\mathrm{s}} \times\left(\mathrm{N}_{\mathrm{RL}}-1\right) \times \mathrm{N}_{\mathrm{RD}}
$$

In this model we seek to bound the radius of the cone defining the rubble pile. To accomplish this, the focus the calculations that follow will be on obtaining the distance traveled by a piece of rubble that is ejected from one of the highest external walls. Partitioning the energy of the explosion among all walls whose fragments are assumed to move yields the amount of energy available for any given wall:

$$
\mathrm{E}_{\text {avail }}=\mathrm{E}_{\mathrm{expl}} / \mathrm{N}_{\mathrm{w}}
$$

where the energy of the explosion, $\mathrm{E}_{\text {expl}}$, is given and $\mathrm{N}_{\mathrm{w}}$ is given by equations (19-21). The next step is to determine the mass(es) and velocity(ies) of the particle(s) of interest.

To begin, we examine a possible path that could be followed by the center-of-mass of the rubble ejected from the highest wall of the building as shown in Figure 4 below. In Figure $4, M_{\text {com }}$ is the mass of the exterior room wall that has been rubblized, $\mathrm{V}_{\text {com }}$ is the velocity of the center-of-mass of the wall rubble, $t_{\text {top }}$ is the time of travel to the highest point of the trajectory, $t_{g r}$ is the time required for the wall center-of-mass to reach the ground, and $\mathrm{X}_{\mathrm{gr}}$ is the distance from the building to the point at which the wall rubble center-of-mass reaches the ground.

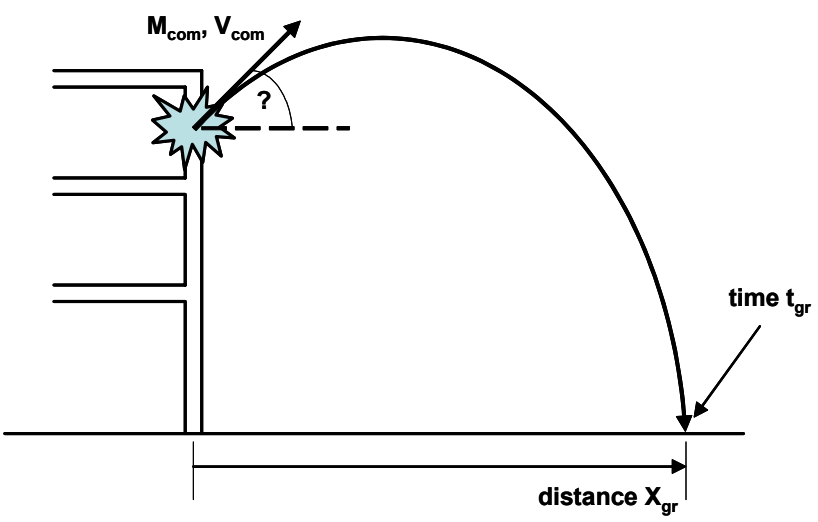

Figure 4: Trajectory of wall section rubble center-of-mass. 


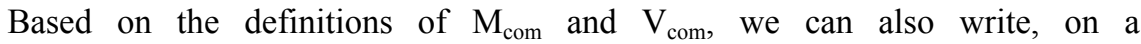
per-exterior-wall basis,

$$
\mathrm{E}_{\text {avail }}=\frac{1}{2} \mathrm{M}_{\text {com }} \mathrm{V}_{\text {com }}^{2}
$$

Additionally, the mass of an exterior room wall, $\mathrm{M}_{\text {com }}$, is given by

$$
\mathrm{M}_{\mathrm{com}}=\mathrm{V}_{\mathrm{we}} \rho_{\mathrm{we}} / \mathrm{N}_{\mathrm{w}, \mathrm{ext}}
$$

where $\rho_{w e}$ is the density of the exterior wall material, and $\mathrm{V}_{\mathrm{we}}$ and $\mathrm{N}_{\mathrm{w} \text {,ext }}$ are given by equations (3) and (20), respectively. Using equation (23) to solve for $\mathrm{V}_{\text {com }}$ yields

$$
\mathrm{V}_{\text {com }}=\sqrt{2 \mathrm{E}_{\text {avail }} / \mathrm{M}_{\text {com }}}
$$

where $\mathrm{M}_{\text {com }}$ is given by equation (24).

We now know the velocity at which the center-of-mass of the rubble debris is assumed to travel until it hits the ground. In order to determine the location of ground impact, several intermediate quantities must be calculated.

First, the starting point (or height $\mathrm{S}_{\mathrm{O}}$ ) of the trajectory shown in Figure 4 is needed. Referring to Figure 5 below, we see that

$$
\mathrm{S}_{\mathrm{O}}=\mathrm{H}-\mathrm{t}_{\mathrm{r}}-\frac{1}{2} \mathrm{~h}_{\mathrm{w}}
$$

where $h_{w}$ is the floor-to-ceiling height of the exterior room wall.

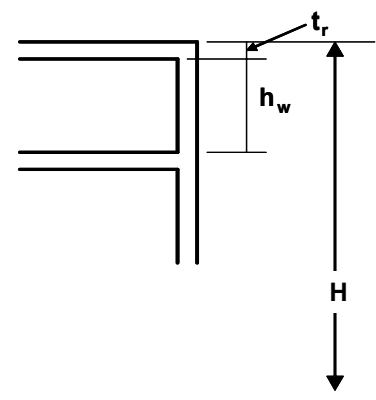

Figure 5: Detail for calculating starting height $\mathrm{S}_{\mathrm{O}}$.

Second, the travel time $t_{\mathrm{gr}}$ must be found. From elementary physics, we recall that the relationship between free-fall distance $S$ and the acceleration due to gravity ' $\mathrm{g}$ ' is given by

$$
\frac{\partial^{2} \mathrm{~S}}{\partial \mathrm{t}^{2}}=-\mathrm{g}
$$

Integrating equation (27) twice and applying initial conditions of velocity and height yields 


$$
\mathrm{S}=\mathrm{S}_{\mathrm{O}}+\mathrm{V}_{\text {com }}(\sin \theta) \mathrm{t}-\frac{1}{2} \mathrm{gt}^{2}
$$

The time $t_{\mathrm{gr}}$ at which the rubble debris center-of-mass hits the ground is found by setting $\mathrm{S}=0$ in equation (28) and solving for time ' $\mathrm{t}$ ' to yield,

$$
\mathrm{t}_{\mathrm{gr}}=\frac{\mathrm{V}_{\text {com }} \sin \theta+\sqrt{\left(\mathrm{V}_{\text {com }} \sin \theta\right)^{2}+2 \mathrm{gS}_{\mathrm{O}}}}{\mathrm{g}}
$$

To maximize the horizontal distance traveled, the material needs to be ejected at an angle of $\theta=\pi / 4$. With this value of $\theta$, equation (29) becomes

$$
\mathrm{t}_{\mathrm{gr}}\left(\theta=\frac{\pi}{4}\right)=\left(\frac{\sqrt{2}}{2}\right) \frac{\mathrm{V}_{\mathrm{com}}}{\mathrm{g}}+\sqrt{\left[\left(\frac{\sqrt{2}}{2}\right) \frac{\mathrm{V}_{\mathrm{com}}}{\mathrm{g}}\right]^{2}+2\left(\frac{\mathrm{S}_{\mathrm{O}}}{\mathrm{g}}\right)}
$$

Finally, the horizontal distance traveled at the time of impact given by equation (30) is simply the product of the horizontal component of the velocity of the rubble debris center-of-mass and the quantity $t_{\mathrm{gr}}$, or,

$$
\mathrm{X}_{\mathrm{gr}}=\mathrm{V}_{\text {com }} \cos \left(\frac{\pi}{4}\right) \mathrm{t}_{\mathrm{gr}}\left(\theta=\frac{\pi}{4}\right)
$$

If a value of $\theta=0$ were used instead of $\theta=\pi / 4$, then $\mathrm{t}_{\mathrm{gr}}$ and $\mathrm{X}_{\mathrm{gr}}$ are given by

$$
\begin{array}{r}
\mathrm{t}_{\mathrm{gr}}(\theta=0)=\sqrt{2\left(\frac{\mathrm{S}_{\mathrm{O}}}{\mathrm{g}}\right)} \\
\mathrm{X}_{\mathrm{gr}}(\theta=0)=\mathrm{V}_{\text {com }} \sqrt{2\left(\frac{\mathrm{S}_{\mathrm{O}}}{\mathrm{g}}\right)}
\end{array}
$$

\section{Comparison of model predictions}

Both of the models developed in this study were run for a four-story unreinforced concrete (density $145 \mathrm{lb} / \mathrm{ft}^{3}$ ) building with four rooms on each floor. The building was $22 \mathrm{ft}$ high with 6 in. exterior walls, 3 in. interior walls, a 6 in. roof, and had a $20 \mathrm{ft} \times 21 \mathrm{ft}$ footprint. A bulk-up factor of 1.5 and a window effects factor of 0.9 were used in the model calculations. Adjacent buildings were assumed to be $9 \mathrm{ft}$ away from the outermost wall of the building of interest.

Although the rubble pile dimensions are independent of the weapon charge used to explode the building in the first-order model, the first-principles based model requires this information as input. For the engagement scenarios anticipated, charge-fills are expected to range from $0.5 \mathrm{~kg}=1.1 \mathrm{lbs}$ TNT for small mortars up to $10 \mathrm{~kg}=22 \mathrm{lbs}$ TNT for Howitzers. As such, a charge of 10 lbs TNT was selected for running the first-principles based model.

In order to run the first-principles model the weight of the charge first had to be converted into an energy delivered. While there are several measures of 
explosive strength given the weight of a charge, to be conservative, a value of $0.8 \times 10^{6} \mathrm{~J} / \mathrm{kg}$ ( or $3.6 \times 10^{6} \mathrm{~J}$ for $10 \mathrm{lbs}$ of TNT) was used in this study. Table 1 below summarizes the main rubble pile characteristics produced by both models for the geometry, material, and loadings described.

Table 1: $\quad$ Rubble pile dimensions as calculated by models.

\begin{tabular}{|l|c|c|c|}
\hline $\begin{array}{l}\text { Rubble Pile } \\
\text { Dimension }\end{array}$ & $\begin{array}{c}\text { First- } \\
\text { Order } \\
\text { Model }\end{array}$ & $\begin{array}{c}\text { First- } \\
\text { Principles } \\
\text { Model }\left(\boldsymbol{\theta}_{\mathbf{4}} \mathbf{4 5}^{\mathbf{0}}\right)\end{array}$ & $\begin{array}{c}\text { First- } \\
\text { Principles } \\
\text { Model }\left(\boldsymbol{\theta}=\mathbf{0}^{\mathbf{0}}\right)\end{array}$ \\
\hline Radius $\left(\mathrm{r}_{\mathrm{c}}\right), \mathrm{ft}$ & 20.5 & 50.8 & 42.6 \\
\hline Height $\left(\mathrm{h}_{\mathrm{c}}\right), \mathrm{ft}$ & 4.8 & 0.79 & 1.12 \\
\hline $\begin{array}{l}\text { Stack-up Height (DD'), } \\
\text { in }\end{array}$ & 0.35 & 22.32 & 18.82 \\
\hline
\end{tabular}

For the $10 \mathrm{lbs}$ TNT charge considered, the first-principles based model clearly predicts a rubble pile radius far in excess of the first-order model. As expected, assuming a $45^{\circ}$ trajectory for the rubble pile increased still further the distance traveled by the rubble center-of-mass. For larger charges, these discrepancies are further increased. Clearly at this point empirical data is needed to verify the predictive capabilities of these various models.

\section{Summary and conclusions}

Two models have been successfully developed to characterize the rubble pile created by the collapse of building. In both models, we assumed complete rubblization of the building and developed a rubble profile model using the size and composition of the collapsed structure to predict the rubble volume. These profile models include the size of footprint area surrounding the original building as well as the height of rubble pile at its center and along its periphery. The dimensions of the rubble pile have been adjusted to include the effects of buildings adjacent to the original collapsed building. At this stage of this effort, empirical data is needed to verify the predictive capabilities of the various models and processes developed.

\section{Acknowledgements}

The UMR co-authors would like to acknowledge the support of $21^{\text {st }}$ Century Systems, Inc. for providing the support that made this study possible.

\section{Reference}

[1] Yarimer, E., and Brown, C.D., "The Effect of Rubble Accumulation on the Mechanics of Demolition by Rapid Collapse." Structures Under Shock and Impact IV, N. Jones and C. Brebbia, eds, WIT Press, UK, pp. 25-33, 1996. 